\title{
Morphology of Helminth Parasites in Salmo Trutta Fario and Schizothorax Plagiostomus in Gurez Valley of Jammu \& Kashmir, India
}

\author{
Bashir Ahmad Sheikh*, Fayaz Ahmad and Tanveer A Sofi \\ Department of Zoology, University of Kashmir, Srinagar, India
}

Received: June 20, 2018; Published: June 27, 2018

*Corresponding author: Bashir Ahmad Sheikh, Department of Zoology, University of Kashmir, Srinagar-190006, India

\begin{abstract}
The present study was carried out from May 2013 to May 2015 on helminth parasites of Salmo trutta fario and Schizothorax plagiostomus of Gurez Valley. Out of 210 specimens of Salmo trutta and 126 specimens of Schizothorax plagiostomus examined during the present study, 49 and 35 respectively were infected with different types of helminth parasites. The recovered parasites during the study include Adenoscolex oreini; Rhabdochona guptii in S. trutta and Adenoscolex oreini; Rhabdochona guptii and Camallanus fotedari in S. plagiostomus. These parasite species were identified on the basis of whole worm recovery for the first time from this region; collected from fishes of Gurez valley and the different localities of Gurez Valley viz.; Baktoor, Dawar, Achoora, Barnai, PTL form new locality records for these Helminth species, as mentioned against each.
\end{abstract}

Keywords: Salmo Trutta Ffario; Schizothorax plagiostomus; Gurez Valley; Adenoscolex; Rhabdochona; Camallanus

\section{Introduction}

Gurez, as geographically isolated from the Valley of Kashmir with diverse topographical features, has attained a unique position in the state of Jammu and Kashmir so far as its natural beauty, less anthropogenic load, high altitude, less pollution of natural resources, high altitude lakes, series of mountain peaks and the mighty Kishenganga River is concerned. Two main human activities viz; industrialization and urbanization are among the risk factors of devastating the environment which seem to be a dream here, and as such will not deteriorate the environment. The origin of Kishenganga river is at Koubal from Krishansar Lake in the vicinity of Sonamarg and runs northwards to Badoab village where it meets a tributary from the Drass side and runs westwards along the Line of Control in Jammu and Kashmir. The Neelum River is 245 kilometers long; it covers 50 kilometers in Jammu and Kashmir and the remaining 195 kilometers in Azad Kashmir. Kishenganga River, 150 $\mathrm{kms}$ in length is famous for having world class trout in it. There are many varieties of trout and other fishes in it. The most prominent amongst them are Snow Trout (Shizothorax), found predominantly in Tilail area Schizothorax plagiostomum, Heckel, 1938 locally known as 'Khont'.

Fishes are hosts to representative of three major groups of helminthes- the Platyhelminths (flatworms), Nematodes (round worms) and Acanthocephalans (spiny headed worms). The life cycles of most fish nematode parasites require an intermediate host for their completion, The Rhabdochona spp. require an intermediate host to complete their life cycle. Morphological, taxonomical and ecological studies of fish parasites are important areas of research. Although taxonomy and ecology of helminth parasites has been studied and elucidated all over India, including Kashmir but no attention has been paid in this field in Gurez valley of Jammu and Kashmir. In fact this is a virgin area with regard to parasitic information and need to be explored thoroughly.

\section{Materials and Methods}

\section{Study Area and Sampling}

During the present study the fish host examined for helminth parasite infestation includes Brown Trout (Salmo trutta fario) and Snow Trout (Schizothorax plagiostomus) in Gurez valley. The Fishes were collected from the Kishenganga River at different sites viz.; PTL (Tulail, Barnoi, Budoab \& Kashpat), Dawar (Dawar, Mastan and Achoora) and Buktoor, with the help of local experienced fishermen and common people. The fishes were brought alive or fresh to the temporary laboratory maintained at Dawar- the capital of Gurez. The collection was done on seasonal basis, and about 80 specimens were dissected per season. For the collection of endoparasites, 
the fishes were dissected mid-ventrally and before removing the internal organs, the body cavity was thoroughly examined for parasites. Various organs like liver, bladder, heart, etc were removed and kept in separate petridishes containing normal saline $0.65 \%$ $\mathrm{NaCl}$ ) [1]. The alimentary canal being the obvious part of entry for many kinds of parasitic infestations was removed completely and split open longitudinally and placed in petridishes containing saline water to which a few crystals of menthol were added so that the parasites which were firmly anchored to the lumen of the intestine were easily detached without causing any damage or distortion to the body of the parasite. Other organs were examined in the same manner by dissection and teasing with the help of brushes and needles. However, maximum numbers of parasites were collected from the alimentary canal of fish. Parasites collected from each fish were counted separately and regular record of the collection was maintained.

\section{Photography \& Photomicrography}

Light microscopy was conducted under Olympus Research microscope (Magnus MLM; 100705686) with lens combination of, 10X, and 15X eye pieces and 4X, 10X, 20X, 40X and 100X objectives. The drawings for identification purposes were made to scale with the help of prism type camera-lucida. The Photographs were taken with the help of Sony Digital SLR Camera Model Number (DSLR A200). Photomicrography was conducted with DP - 12 Digital Camera attached to Olympus Research Microscope in the department of Zoology. The measurements were made with the help of objective (stage) micrometer only, by drawing the scale of the objective micrometer under different lens combinations and then taking measurements directly from the drawings drawn under the same magnifications. Objective and ocular micrometers; by standardizing the ocular micrometer with the objective (stage) micrometer and later measuring the parasites or part/s with the help of ocular micrometer only.

\section{Results and Discussion}

The recovered parasites during the study include Adenoscolex oreini; Rhabdochona guptii in S. trutta; and Adenoscolex oreini; Rhabdochona guptii and Camallanus fotedari in S. plagiostomus.

\section{Cestoda}

Adenoscolex Oreini Fotedar, 1958 [2] (Figures 1 \& 2)

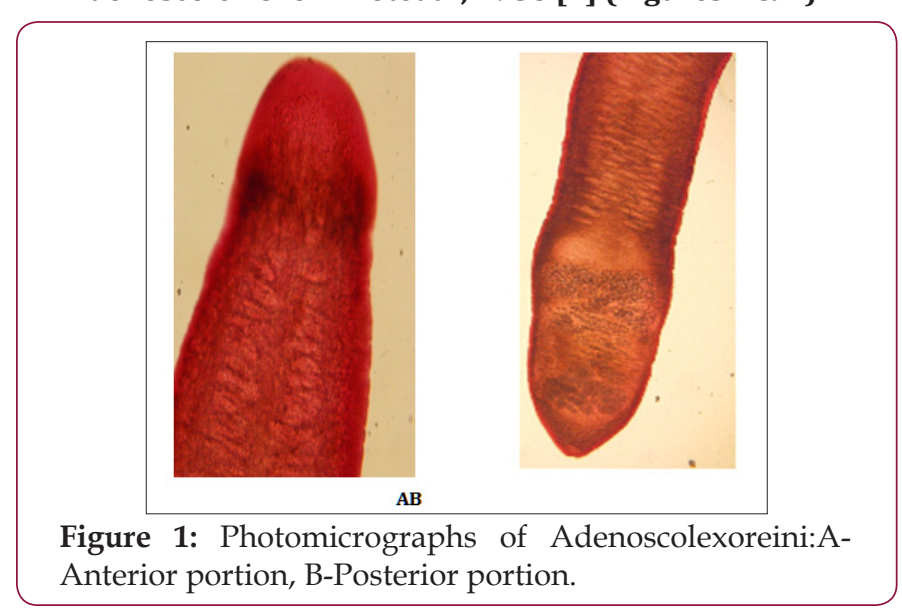

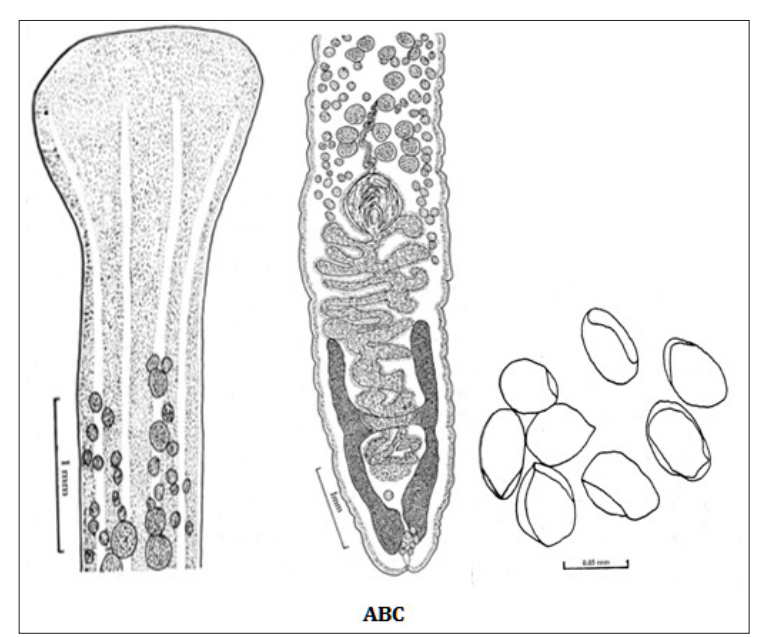

Figure 2: Camera Lucida drawing of AdenoscolexoreiniFotedar, 1958.

A-Anterior Region;

B-Posterior region; C-Eggs.

i. Generic Diagnosis: Smooth scales with well marked gland cells which are continued in body region, cirrus sac and utero-vaginal canal open separately at the beginning of posterior seventh of the body; lower horns of ovary bent inwards giving the appearance of inverted ' $A$ ', uterine coils extended beyond anterior horns of ovary but never anterior to cirrus sac; well developed receptaculum seminis; vitelline fields partly cortical and partly medullary being mostly at the level of inner longitudinal muscle layer; post-ovarian vitelline follicles present [3].

ii. Species Diagnosis: Comparatively smaller than Adenoscolex fotedari (about 38mm); No. of excretory vesicles 1418; Shape of ovary like inverted 'A'lower horns of which are strongly bent inwards. While as in Adenoscolex fotedari ovary is $\mathrm{H}$-shaped and the two horns of ' $\mathrm{H}$ ' are not bent on either side; no. of excretory vesicles 18-30 (Table 1).

iii. Description: Body elongated with unarmed scolex. Mature worm broader and thicker in posterior part of the body. Gland cells developed extensively in scolex region being visible to naked eye, extended posterior in 3 well-developed columns for more than 3 quarter of anterior body length. A single set of male and female genital organs open separately to posterior end through male and female genital openings. Testis and vitellaria scattered while other genital organs restricted to posterior $1 / 7$ th of body. Testis rounded, extended from scolex to cirrus pouch, bounded by vitelline follicles, vas deferens loosely convoluted tube, median anterior to cirrus sac. Cirrus sac muscular, pear shaped. Vitellaria numerous. Ovary single at $1 / 7$ th posterior end of the body more or less $\mathrm{H}$ shaped. Two long limbs connected by a transverse ovarian isthumus. Uterus coiled structure containing ova at different stages of development unite with vagina forming a utero-vaginal chamber to open exterior by female genital aperture. Capsules operculate ovoid, boat shaped with a small protuberance near basal region. 
Table 1: Comparative characteristics (measurements in mm) of Adenoscolex oreini Fotedar, 1958.

\begin{tabular}{|c|c|c|c|c|c|}
\hline Particulars & Fotedar [2] & Fayaz [3] & Ashiq [4] & Akhter et al. [5] & Present Study \\
\hline Total body length & $30-35 \times 1.45-1.75$ & 49.5 & 30.5 & 51 & $32-37$ \\
\hline Scolex & Nearly 2 & $0.87-1.64$ & $1.38 \times 0.90$ & $0.84-1.06$ & $0.90-1.40$ \\
\hline Neck & $1.2-1.7 \times 1.3-1.7$ & $1.0-1.1$ & -------- & $1.0-1.1$ & $0.9-1.1$ \\
\hline Testes & ---------- & $\begin{array}{c}0.144-0.224 \times 0.048- \\
0.192\end{array}$ & $0.18-0.21 \times 0.09-0.16$ & $0.15-0.24 \times 0.050-0.19$ & --------- \\
\hline Vas deference & -------- & -------- & $0.5 \times 0.45$ & -------- & --------- \\
\hline Ovary length & -------- & -------- & 2.15 & -------- & -------- \\
\hline Ovary width & -------- & -------- & 0.5 & -------- & --------- \\
\hline Wings of ovary & $1.9-2.2 \times 0.25-0.37$ & $1.4-2.7 \times 0.17-0.3$ & --------- & $1.46-2.5 \times 0.17-0.5$ & --------- \\
\hline Ovary isthmus & --------- & $0.31-0.71 \times 0.07-0.16$ & -------- & $0.35-0.73 \times 0.07-0.18$ & $0.33-0.71 \times 0.06-0.15$ \\
\hline Egg & --------- & $\begin{array}{c}0.052-.076 \times 0.028- \\
.056\end{array}$ & $0.52-0.06 \times 0.23-0.26$ & $\begin{array}{c}0.059-0.074 \times 0.028- \\
0.059\end{array}$ & $\begin{array}{c}0.050-0.071 \times 0.027- \\
0.055\end{array}$ \\
\hline Host & Schizothorax spp. & Schizothorax spp. & Schizothorax spp. & Schizothorax spp. & $\begin{array}{c}\text { Salmo trutta fario and } \\
\text { Schizothorax plagios- } \\
\text { tomus }\end{array}$ \\
\hline Site & Intestine & Intestine & Intestine & Intestine & Intestine \\
\hline
\end{tabular}

iv. Location: Intestine; Host: Salmo trutta fario and Schizothorax plagiostomus; Locality: Buktoor, Achoora, Dawar, Markoot, Barnai, Budoab (PTL)

v. Remarks: From the above observations with regard to morphological characteristics/measurements of the parasite, it shows close resemble with Adenoscolex oreini. The identifying characters include; scolex and neck, Body length 32-37 mm, ovary isthamus and egg size. The studies are in close confirmity with that of (2-5). The identified parasite Adenoscolex oreini is first record of its nature from the Gurez valley of Jammu and Kashmir [4,5].

\section{Nematoda}

\section{Rhabdochona Guptii Chishti \& Bakshi [6], (Figures 3 \& 4)}

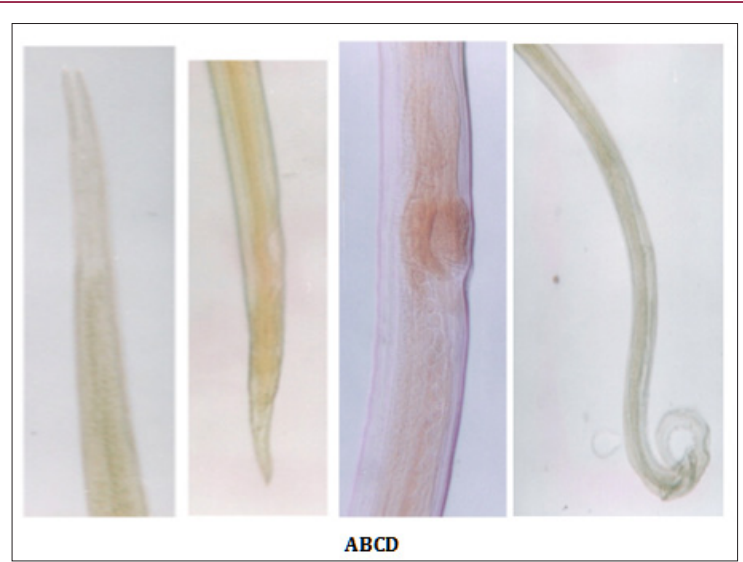

Figure 3: Photomicrographs ofRhabdochonaguptii, A-Anterior end of Female,

B-Posterior end of Female,

C-Vulva of Female,

D-Posterior end of male.

I. Generic Diagnosis: Head and body bare, mouth with two lips. Buccal capsule funnel shaped anteriorly and provided in this region with longitudinal ribs terminating anteriorly in point- ed teeth; oesophagus of moderate length, composed of two distinct parts.
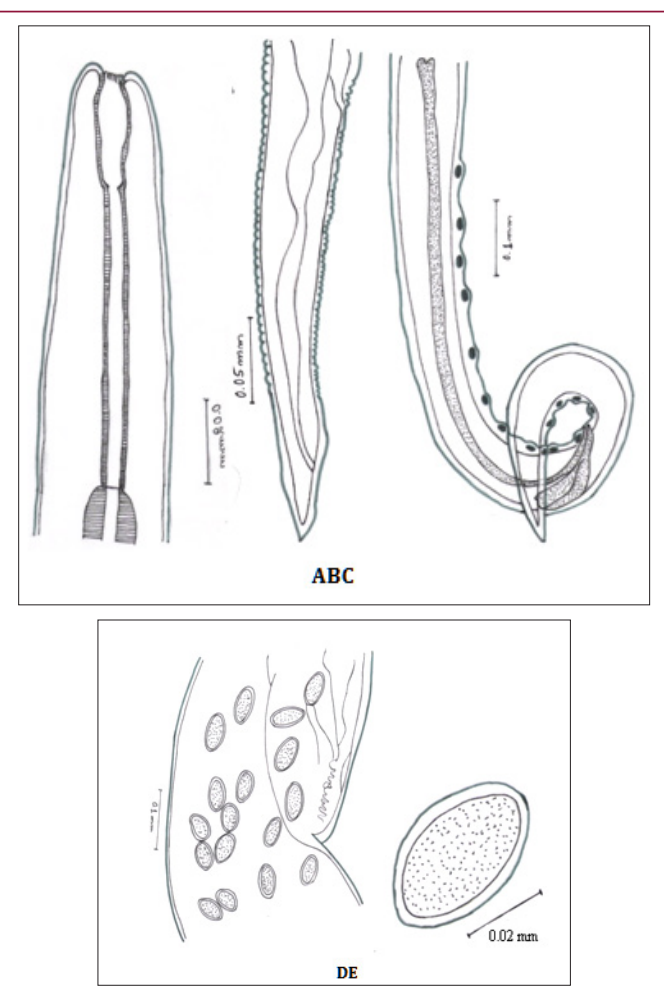

Figure 4: Camera Lucida drawing of Rhabdochonaguptii, Chishti \&Bakshi, 1990.

A-Anterior end of Female,

B-Posterior end of Female,

C-Posterior end of male,

D-Vulvar region of Female,

E-Egg

a) Male: Tail conical, pointed, curved ventrad; caudal alae narrow; numerous, simple, pre-anal papillae and 3 to 6 pairs of post-anal papillae; spicules unequal. 
b) Female: Tail straight and elongate; vulva in middle region of body; uterine branches opposed. Oviparous, eggs elliptical. Parasitic in intestine of fresh water fishes.

II. Species Diagnosis: Comparatively smaller than other known species; Unequal spicules; 14 pairs of caudal papillae with length ratio 1:10; tail length 0.4-0.42 and 0.2-0.23 in males and females respectively.

III. Description: Rhabdochona is the nematode parasite in the intestines of fish. Head is somewhat truncated and broader than tail end. Head is bare, mouth with 3 lips. Buccal capsule funnel shaped anteriorly and provided in the region with longitudinal ribs, terminating anteriorly in pointed teeth. Tail is pointed and sharply tapering behind the anus. Oesophagus is of moderate length, composed of two digestive points. In male tail are conical, pointed, ventrally curved and caudal alae narrow. There are numerous simple pre-anal papillae and post-anal papillae. Spicules unequal. In females, tail is straight and elongated. The vulva is located behind the middle level of the body in a shallow depression surrounded by swollen lips. It lies close to the tail. Uteri are well developed and filled with numerous eggs. The eggs are without any polar filament or projections on the shell (Table 2).

Table 2: Comparative characteristics (measurements in $\mathrm{mm}$ ) of Rhabdochona spp.

\begin{tabular}{|c|c|c|c|c|c|c|}
\hline Particulars & R. oreini Dhar [7] & $\begin{array}{c}\text { R. jammuensis } \\
\text { Dhar [7] }\end{array}$ & R. tori Dhar [7] & $\begin{array}{c}\text { R. imalayai Dhar } \\
\text { [7] }\end{array}$ & $\begin{array}{c}\text { R. guptii Chishti } \\
\text { and Bakshi [6] }\end{array}$ & Present study \\
\hline Body size male & $6.89-7.95$ & 6.36 & $6.89-7.42$ & $6.059-9.54$ & $5.13-6.09$ & $5.01-6.15$ \\
\hline Body size female & $12.19-15.10$ & 7.5 & $9.0-11.13$ & $10.6-15.9$ & $5.16-6.12$ & $5.20-6.25$ \\
\hline $\begin{array}{c}\text { Male caudal papillae-Pre } \\
\text { cloacal }\end{array}$ & 13 & 7 & 9 & 10 & 9 \\
\hline $\begin{array}{c}\text { Male caudal papillae-Post } \\
\text { cloacal }\end{array}$ & 6 & 5 & 5 & 5 & 5 & 5 \\
\hline Spicule size- longer & $470-500$ & 300 & 595 & 119 & 85 & 500 \\
\hline Spicule size- small & $85-100$ & 50 & $1: 5$ & $1: 3.5$ & 50 & $4: 10$ \\
\hline Spicule length ratio & $1: 5$ & $1: 6$ & 0.55 & 0.58 & $0.4-0.42$ & $0.4-0.45$ \\
\hline Tail length male & 0.58 & 0.11 & 0.38 & 0.23 & $0.2-0.23$ & $0.18-0.22$ \\
\hline Tail length female & 0.48 & 0.5 & Intestine & Intestine & Intestine & Intestine \\
\hline Site & Intestine & Intestine & Jammu & Kargil & Hokersar wetland & Gurez \\
\hline Locality & Jammu & Jammu & & & 50.5 \\
\hline
\end{tabular}

IV. Location: Intestine; Host: Salmo trutta fario and Schizothorax plagiostomus; Locality: Buktoor, Achoora, Dawar, Markoot, Barnai, Budoab (PTL)

V. Remarks: The worm under reference resembles Rhabdochona guptii in having its unequal spicules at the tip and the number of caudal papillae being 14 pairs ( 9 pre-cloacal and 5 post-cloacal) but show some variations from the known description. The length ratio being 1:10 in earlier reported specimens and 1:10.5 in the present specimens. The body size of the female being 5.16$6.12 \mathrm{~mm}$ as against the present specimens which is $5.20-6.25$. The present specimens show many important morphological features in accordance with the previously described species, Rhabdochona guptii Chishti and Bakshi, 1990 to which it is assigned. However, the variations recorded which may be attributed to the change of locality and host species [6].

\section{Camallanus Fotedari Raina \& Dhar [7]; (Figures 5 \& 6)}

I. Generic Diagnosis: Mouth slit like, buccal capsule consisting of two lateral chitinous valves with longitudinal rib like thickenings internally. From the point of junction of the valves, dorsally and ventrally, a trident-shaped chitinous process is directed backwards. A chitinous ring is at junction of valves and oesophagus. Esophagus consisting of a short anterior muscular portion and a long posterior glandular portion enlarged posteriorly.

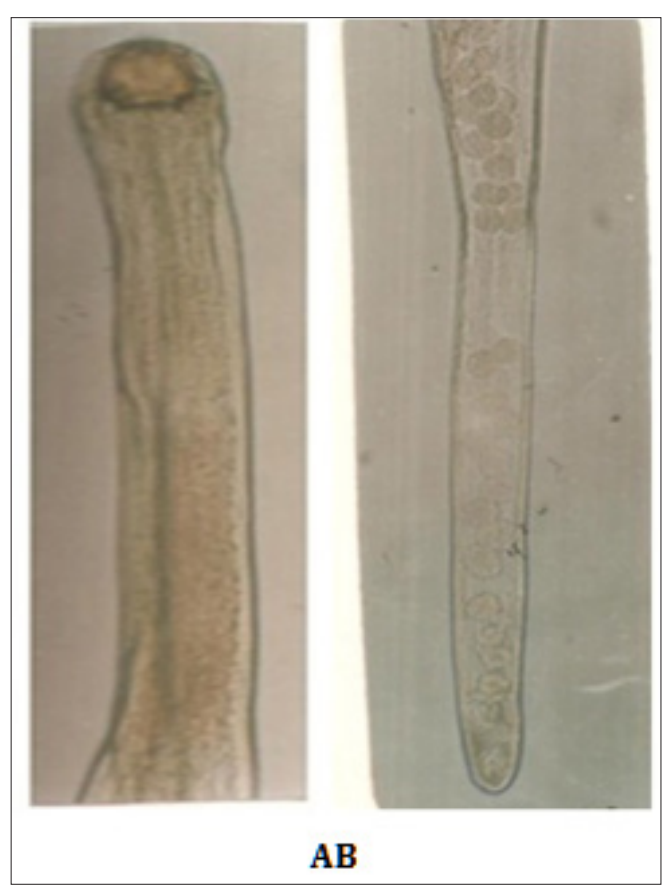

Figure 5: Photomicrographs ofCamallanusfotedari, A- Anterior end, B-Posterior end 


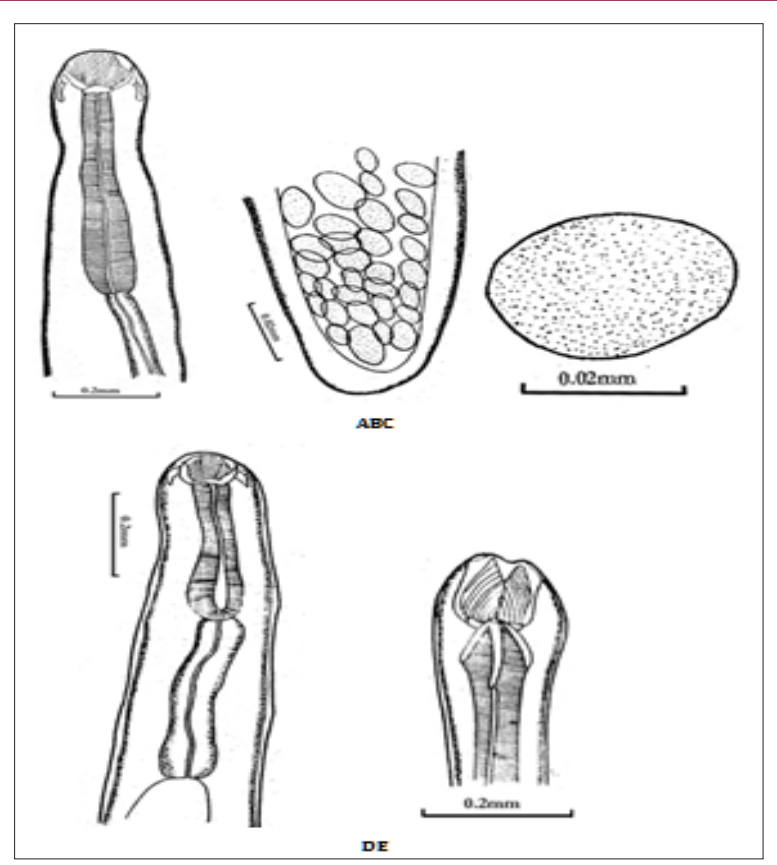

Figure 6: Camera Lucida drawing ofCamallanusfotedari Raina and Dhar, 1972.

A - Anteriorend of female;

B- Posterior region of female;

C - Eggs;

D- Anterior end of male;

E- Posterior end of male.

a) Male: Posterior extremity rolled ventrally; small caudal alae present; about 7 pairs of costiform pre anal papillae, 2 pairs of small adanal and a number of postanal papillae; spicules usually unequal and dissimilar, one feebly chitinized, gubernaculums absent. b) Female: Vulva about middle of body; utri opposed; posterior ovary lacking, viviparous. Parasites of stomach and intestines of fishes, amphibians and reptiles. Larvae in crustaceans.

II. Species Diagnosis: Small worms, measuring 5.700-7.20 $\times 0.12 \times 0.20 \mathrm{~mm}$ and with a broad anterior and tapering posterior end. Mouth terminal, slit-like, with a pair of papillae on each side. Buccal capsule with two lateral chitinous valves. Oesophagus long measuring $0.08 \mathrm{~mm}$. Tail with a characteristic rounded tip; uterus extending upto the tip of the tail and ending blindly. Vagina directed posteriorly. Vulva is located posterior to the middle of the body over a raised area.

III. Description: The worms are long and light brown in colour when alive, with broader anterior end and tapering posterior end. Body small, cylindrical, cuticle finely striated. Thick cuticle covers the body which bears transverse striations. Mouth surrounded by a pair of papillae on each side. A well-developed buccal capsule is present. It is cylindrical and broad in the middle with slight decrease in diameter anteriorly and broad in the middle with only slight decrease in diameter anteriorly and posteriorly. It is continuous without any differentiation into paired lateral valves. Its wall is smooth showing no ridges or striations, except at the anterior end where there are minute and fine vertical ridges. Two pairs of buccal papillae, sub median in position. Anterior oesophagus long, muscular and differentiated into anterior muscular and posterior glandular portions. A nerve ring is present posterior to the buccal capsule (Table 3). Females are stout and very long, ranging in size from $38-58 \mathrm{~mm}$. Maximum breadth from $0.45-0.77 \mathrm{~mm}$. Tail is blunty rounded, bearing two projections at its tip. Uterus extended up to posterior end of tail. Vulva at posterior equatorial level. Cuticle around the vulva is swollen at both ends.

Table 3: Comparative characteristics (measurements in $\mathrm{mm}$ ) of Camallanus fotedari.

\begin{tabular}{|c|c|c|c|}
\hline Particulars & Raina and Dhar, 1972 & Parveen, 1985 & Present study \\
\hline \multicolumn{4}{|c|}{ Female specimens } \\
\hline Total length & $1.98-11.92$ & $5.700-7.200$ & $6.80-9.50$ \\
\hline Max. Breadth & $0.12-0.52$ & $0.12-0.20$ & $0.12-0.40$ \\
\hline Oesophagus length (anterior) & $0.16-0.66$ & $0.32-0.08$ & $0.25-0.50$ \\
\hline Oesophagus length (posterior) & $0.28-0.87$ & $0.5-0.09$ & $0.25-0.70$ \\
\hline Buccal capsule (Length) & $0.07-0.50$ & 0.08 & $0.1-0.20$ \\
\hline Buccal capsule (Breadth) & $0.5-0.13$ & 0.06 & ----------- \\
\hline Distance from anterior end to vulva & $2.17-6.82$ & 2.24 & $2-3$ \\
\hline Tail length & $0.28-1.45$ & $0.16-0.20$ & $0.30-1.10$ \\
\hline Site & Intestine & Intestine & Intestine \\
\hline Locality & Dal Lake, Sgr. & Srinagar & Gurez \\
\hline
\end{tabular}

IV. Location: Intestine; Host: Schizothorax plagiostomus; Locality : Buktoor, Achoora, Dawar, Markoot, Barnai, Budoab (PTL)

V. Remarks: Raina and Dhar, 1972 reported Camallanus fotedari n.sp. from the intestines of Nemachilus kashmirensis in Kashmir. The present specimen shows its morphological features in close accordance with that of $(7,8)$ with some minor variations.
Thus the present species is assigned to the Camallanus fotedari.

\section{Acknowledgement}

The authors are greatly thankful to the Department of Zoology, University of Kashmir for the facilities they provided. The financial help rendered by University Grants Commission, New Delhi through (FIP) "Faculty Improving Programme" is duly acknowledged. 


\section{References}

1. Meyer MC, Olsen OW (1975) Essentials of parasitology. ( $\left.2^{\text {nd }} e d n\right), W m C$ Brown Co, Iowa, USA.

2. Fotedar DN (1958) On a new caryophyllaeid cestode, Adenoscolex oreini Gen. et. sp. nov. from fresh-water fish in Kashmir, and a note on related genera. J Helminthol 32(1-2): 1-16.

3. Fayaz A (1993) Trematode and Cestode Parasites of Pisces and Aquatic aves of Kashmir, with Histology and Histopathology of Genus Adenoscolex Fotedar, 1958. Thesis of University of Kashmir, Srinagar, India.

4. Ashiq HR (2008) Determinants of Rich Helminth Parasite Communities in Native Fish Species in Comparison to Poor Helminth Communities in Exotic Fish Species from Jhelum. Thesis of University of Kashmir, Srinagar, India.

5. Akhter S, Fayaz A, Chishti MZ (2008) Infection Dynamics of Bothriocephalus acheilognathi in The Copepod Intermediate Host. Oriental Sci 15: 55-59.

6. Chishti MZ, Bakshi S (1990) On Rhabdhochona guptii n. sp. from the intestines of Cyprinus carpio spicularis, a fresh water fish from Hokarsar (wetland) in Kashmir. Indian Journal of Parasitology 16(2): 161-163.

7. Dhar RL (1972) Studies on the Helminth Parasites of Fishes of Jammu and Kashmir. Thesis, University of Kashmir, Srinagar, India.
(C) (P) This work is licensed under Creative Commons Attribution 4.0 License

Submission Link: https://biomedres.us/submit-manuscript.php

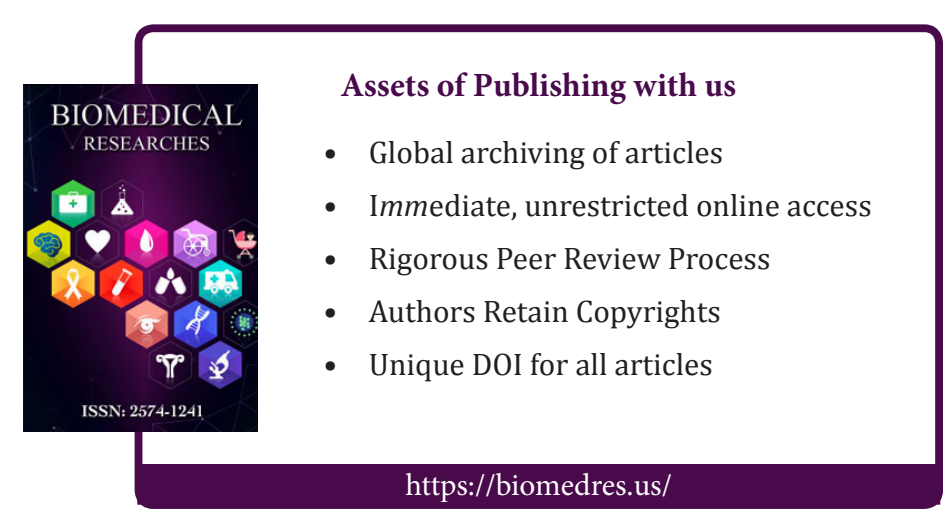

